REVISTA DE DERECHO UNED, NÚM. 28, 2021

\title{
ESPAÑA Y SUS VÍCTIMAS. LA PROTECCIÓN DE LAS VÍCTIMAS DEL FRANQUISMO Y DE ETA, UNA CUESTIÓN DE DERECHOS HUMANOS
}

\author{
SPAIN AND ITS VICTIMS. THE PROTECTION OF THE VICTIMS \\ OF FRANCOISM AND ETA, A HUMAN RIGHTS ISSUE
}

\author{
Olatz Alonso Guevara ${ }^{1}$
}

Sumario: I. Introducción. II. Las víctimas y sus derechos. II.1. Derecho a la verdad, justicia y reparación. III. España y la protección de las víctimas: marco general. IV. las víctimas de la Guerra Civil y el franquismo. IV.1. La ley de memoria histórica. IV.2. Judicialización de los crímenes del franquismo. V. las víctimas de ETA. VI. Victimas de primera y de segunda. VII. Conclusiones. VIII. Bibliografía. Otros documentos referenciados.

Resumen: Durante el siglo xx España fue escenario de dos situaciones de violencia política que generaron diferentes vulneraciones de derechos y víctimas. Aunque la legislación internacional reconoce el derecho de todas las víctimas a la verdad, justicia y reparación, la atención y protección ofrecida desde el Estado español a las mismas ha dependido de la fuente de la violencia victimizadora, generando regímenes diferentes para las víctimas de la Guerra Civil y el franquismo y las víctimas de ETA. Este desarrollo desigual de las leyes de víctimas en España ha servido para reforzar el relato de una Transición ejemplar y no juzgar los crímenes cometidos durante la guerra ni la dictadura, lo que ha generado nuevas vulneraciones de

1 Periodista especializada en comunicación de conflictos, paz y movimientos sociales por la UAB y estudiante del postgrado de Derechos Humanos y Políticas Públicas, ha trabajado y colaborado en una asociación de apoyo al pueblo saharaui en el ámbito de la Educación para la Transformación Social desde un enfoque de defensa y promoción de los Derechos Humanos.

(C) UNED. Revista de Derecho UNED, núm. 28, 2021 
derechos de las víctimas, a quienes se le niega el acceso a la verdad, la justicia y la reparación.

Palabras clave: víctimas; derechos; violencia política; España; memoria histórica; ETA; verdad, justicia y reparación; Guerra Civil; franquismo; Transición

Abstract: During the 20th century Spain was the scene of two situations of political violence that generated different violations of rights and victims. Although international legislation recognizes the right of all victims to truth, justice and reparation, the attention and protection offered by the Spanish State to these victims has depended on the source of the victimizing violence, generating different regimes for the victims of the Civil War and Francoism and the victims of ETA. This unequal development of the laws of victims in Spain has served to reinforce the story of an exemplary Transition and not to judge the crimes committed during the war or the dictatorship, which has generated new violations of the rights of victims, who are denied access to truth, justice, and reparation.

Keywords: victims; rights; political violence; Spain; historical memory; ETA; truth, justice, and reparation; Civil War; Francoism; Transition

Recepción original: 07-12-2020

Aceptación original: 23-09-2021

\section{INTRODUCCIÓN}

Durante el siglo xx España fue escenario de dos sucesos de violencia política que se saldaron con un importante reguero de víctimas y de vulneraciones de derechos fundamentales: la Guerra Civil (1936-1939) y la posterior dictadura franquista (1939-1975) y la actividad armada de la organización terrorista ETA (Euskadi Ta Askatasuna, 1959-2011).

Sin embargo, no existen experiencias de procesos transicionales dirigidos a establecer la memoria histórica de ambos episodios y la protección ofrecida desde los órganos estatales a las víctimas de uno y otro contexto presentan importantes diferencias que podrían resumirse en el establecimiento de unas como el paradigma de la víctima de graves violaciones de derechos y el olvido de las otras.

"En una comparación entre Europa y España, la función que en aquella cumple el holocausto nazi como eje desde el que sus víctimas 
por excelencia [...] aparecen en el espacio público y se rodean de modelos jurídicos excepcionales, en España, sin embargo, es cumplida por el fenómeno terrorista de ETA. Son sus víctimas, y no las de la guerra civil o las de la represión franquista, las que ocupan ese lugar central"2

Esta percepción desigual de las víctimas se traduce en normativas sectoriales diferentes y desiguales a pesar de que ambos casos podrían englobarse en la categoría de víctimas de la violencia política. Estas distinciones tanto normativas como de reconocimiento social generan diferentes grados de vulneraciones de los derechos a la verdad, la justicia y la reparación de aquellas personas que sufrieron violencia política en España el pasado siglo.

\section{LAS VÍCTIMAS Y SUS DERECHOS}

El derecho internacional reconoce a las víctimas de graves violaciones ciertos derechos cuyo objetivo es, por un lado, reparar el daño causado por dichas vulneraciones y, por el otro, luchar contra la impunidad de quienes cometieron esos crímenes.

El marco normativo en torno a los derechos de las víctimas está regulado en los "Principios y directrices básicos sobre el derecho de las víctimas de violaciones manifiestas de las normas internacionales de derechos humanos y de violaciones graves del derecho internacional humanitario a interponer recursos y obtener reparaciones"3, adoptados mediante la Resolución 60/147 de la Asamblea de Naciones Unidas el 16 de diciembre de 2005. La base de estos principios se encuentra en los instrumentos generales de protección de los Derechos Humanos de todas las personas ${ }^{4}$, cuyo desarrollo en el ámbito específico de las víctimas de delitos ha derivado en los Principios Básicos anteriormente citados.

Estos principios "no pretenden establecer nuevas obligaciones jurídicas internacionales o nacionales, sino únicamente indicar los mecanismos, modalidades, procedimientos para el cumplimiento

2 Landa, J.M. (2018). "Políticas de víctimas de la violencia política en España y el País Vasco: una reflexión a la luz del holocausto". Revista General de Derecho Penal, $n^{\circ} 29$.

3 En adelante "los Principios Básicos".

4 Como la Declaración Universal de los Derechos Humanos, el Pacto Internacional de Derechos Civiles y Políticos, la Convención contra la Tortura y Otros Tratos o Penas Crueles, Inhumanos o Degradantes y el Convenio Europeo para la Protección de los Derechos Humanos y las Libertades Fundamentales. (Mínguez, X. (2015). "Euskal Herria. Algunas claves para avanzar en la construcción de paz". En Mundubat (ed.), Aprendiendo de los procesos de paz. Bilbao: Gakoa). 
de las obligaciones jurídicas existentes conforme a las normas internaciones [sic] de derechos humanos y al derecho internacional humanitario" 5 y deberían ser la referencia a la hora de diseñar y desarrollar políticas de justicia transicional o de reparación.

El texto define a la víctima como "toda persona que haya sufrido daños, individual o colectivamente, incluidas lesiones físicas o mentales, sufrimiento emocional, pérdidas económicas o menoscabo sustancial de sus derechos fundamentales, como consecuencia de acciones $\mathrm{u}$ omisiones que constituyan una violación manifiesta de las normas internacionales de derechos humanos o una violación grave del derecho internacional humanitario", así como sus familiares cercanos o las personas a su cargo y las personas que hubiesen podido sufrir daños al atenderles cuando se encontraban en peligro ${ }^{6}$.

Para las personas que se encuentren en la situación anteriormente especificada, Naciones Unidas reconoce su derecho a un recurso efectivo mediante el acceso a la justicia, una reparación adecuada, rápida y efectiva y el acceso a información sobre las violaciones y los mecanismos de reparación disponibles ${ }^{7}$. Para ello, los Estados se ven en la obligación de adoptar medidas legislativas, investigar y actuar contra los responsables, garantizar a las víctimas un acceso equitativo y efectivo a la justicia y proporcionarles recursos eficaces que lleven a una reparación del daño sufrido ${ }^{8}$.

En lo concerniente al acceso a la justicia, las víctimas tienen derecho al acceso no solo a procedimientos judiciales, sino también a los dispuestos por órganos administrativos o de otro tipo. Ante este derecho, los Estados se ven en la obligación de informar a las víctimas sobre los recursos de los que disponen, así como la adopción de medidas que minimicen los inconvenientes que pudieran causarse a las víctimas, facilitarles la asistencia necesaria y garantizar su derecho a interponer un recurso.

En cuanto a la reparación, los Principios Básicos establecen que ésta deberá ser proporcional a la gravedad y el sufrimiento y para

5 Cruz, L. M. (2010). "El derecho de reparación de las víctimas en el derecho internacional. Un estudio comparativo entre el derecho internacional de responsabilidad estatal y los principios básicos de reparación de víctimas de derechos humanos". Revista de Derecho Político, pág. 194.

6 A/RES/60/147 (2005) "Principios y directrices básicos sobre el derecho de las víctimas de violaciones manifiestas de las normas internacionales de derechos humanos y de violaciones graves del derecho internacional humanitario a interponer recursos y obtener repararación, Asamblea de Naciones Unidas.

7 Íbid.

8 Íbid. 
ello comprometen a los gobiernos a diseñar e implementar programas de reparación", que englobarían "todas aquellas medidas que se pueden adoptar para resarcir los diversos tipos de daño que puedan haber sufrido las víctimas como consecuencia de ciertos crímenes"10 y conforman cinco tipos: restitución, indemnización, rehabilitación, satisfacción y garantías de no repetición.

La restitución equivaldría a la rehabilitación de la situación de la víctima antes de la vulneración, la indemnización hace referencia a la compensación económica de aquellos daños que puedan cuantificarse monetariamente, que deberá ser apropiada y adecuada a la gravedad y circunstancias de cada víctima, y la rehabilitación se dirige a garantizar la atención médica y psicológica de la persona cuyos derechos fundamentales han sido vulnerados.

Las medidas de satisfacción y las garantías de no repetición, en cambio, están enfocadas más a largo plazo y a la prevención de futuras violaciones ${ }^{11}$. Las primeras equivaldrían a las medidas no monetarias como el cese de las violaciones, el conocimiento de la verdad, la búsqueda de las personas desaparecidas, sanciones a los responsables, disculpas públicas con reconocimiento de los hechos, homenajes y la transmisión en el sistema educativo de lo sucedido y los aprendizajes derivados. Entre las acciones dirigidas a impedir que vuelvan a sucederse situaciones de vulneraciones, destacan las referidas a reformas institucionales (fuerzas de seguridad y cuerpos armados del Estado, formación de funcionarios y establecimiento de códigos de conducta, independencia del poder judicial y ajuste de las normas y procedimientos a los estándares internacionales, entre otros) y a la promoción de una cultura de paz y de respeto de los Derechos Humanos.

\section{II.1. Derecho a la verdad, justicia y reparación}

Así, la comunidad internacional reconoce el derecho a la verdad, a la justicia y a la reparación de las víctimas de violaciones graves de derechos humanos (sea por su naturaleza o magnitud) y atribuye la responsabilidad de respetar, proteger y aplicar esos derechos a los

9 Cruz, L. M. (2010). ob. cit.

10 Greiff, P. D. (2011). “Justicia y reparaciones". En E. F. Reátegui, Justicia transicional: manual para América Latina. Brasilia: Comisión de Amnistía, Ministerio de Justicia; Nueva York: Centro Internacional para la Justicia Transicional; pág. 409

11 Cruz, L. M. (2010). ob. cit. 
Estados ${ }^{12}$. Estos imperativos suponen "una concepción más amplia de la justicia, que va más allá de la satisfacción de reclamos individuales y que incluye reconocimiento, confianza cívica y solidaridad social" 13 .

El derecho a la verdad es un derecho de las víctimas de violaciones de Derechos Humanos, así como de sus familiares y de la sociedad en su conjunto, de acceder a información veraz y lo más completa posible la causa y manera en que sucedieron esas vulneraciones, así como quiénes fueron los autores ${ }^{14}$. Es además inalienable, inderogable y no limitable y su negación puede acrecentar la desconfianza respecto a las instituciones, realizar un nuevo daño a la sociedad y profundizar divisiones que podrían derivar en nuevas violaciones de derechos fundamentales ${ }^{15}$. Aquí es, precisamente, donde radica su importancia en lo que a este trabajo atañe, ya que "en contextos transicionales, el logro de una verdad completa, veraz, imparcial y socialmente construida, compartida, y legitimada es un elemento fundamental para la reconstrucción de la confianza ciudadana en la institucionalidad estatal"16.

Presenta así una dimensión individual, concerniente al derecho de las víctimas y sus familiares de conocer las causas de la victimización, sus razones y circunstancias, así como la evolución de las investigaciones, la identidad de los responsables y la situación de las personas desaparecidas ${ }^{17}$. Por otro lado, el reconocimiento de la verdad cuenta también con una dimensión colectiva, ya que juega un papel de prevención ante posibles repeticiones de vulneraciones y, al mismo tiempo, se refiere al derecho del conjunto de la sociedad de conocer su pasado ${ }^{18}$.

La garantía del derecho a la verdad se relaciona de esta forma con la interpretación de la justicia como solidaridad social. Este tipo de solidaridad se refiere a la "empatía característica de aquellas personas

12 Amnistía Internacional. (2007). Verdad, Justicia y Reparación. Creación de una Comisión de la verdad efectiva. London: Amnistía Internacional.

13 Greiff, P. D. (2011). ob. cit. pág. 413

14 Comisión Interamericana de Derechos Humanos (2014) Derecho a la verdad en América OEA/Ser.L/V/II.152 Doc.2

15 Amnistía Internacional. (2017). Afrontar el pasado para construir el futuro: Verdad, justicia y reparación en el contexto del País Vasco. Madrid: Amnistía Internacional.

16 Comisión Interamericana de Derechos Humanos (2014) ob. cit. pág.20

17 Íbid.; Amnistía Internacional. (2007) ob. cit; Payero, L. (2016). "Justicia de Transición en España: claves para aprobar una asignatura pendiente". Revista de Paz y Conflictos, $\mathrm{n}^{\circ} 1$, vol. 9, págs. 209-234.

18 Íbid. 
que tienen la disposición de ponerse en el lugar de otras"19 y el esclarecimiento de los acontecimientos influye en esa solidaridad de dos maneras $^{20}$. Por un lado, despertará la empatía del resto de la sociedad respecto las víctimas al conocerse las violaciones que han sufrido y, por otro, permitirá a las víctimas reconciliarse con la sociedad, ya que la verdad "ofrece un nuevo "contrato social" en el que su dignidad y sus intereses son ampliamente reconocidos" y, por tanto, "tendrán razones para interesarse en intereses comunes"21.

Como ya se ha señalado antes, el derecho a la justicia supone la garantía de las víctimas de tener acceso a un procedimiento justo e imparcial. Una respuesta del sistema judicial adecuada a las demandas, necesidades y derechos de las víctimas influirá en la confianza que la ciudadanía tiene tanto entre individuos como en las propias instituciones, en tanto que el sistema judicial es, al mismo tiempo, dependiente y catalizador de dichas confianzas ${ }^{22}$.

Según el análisis de Rawls, los sistemas jurídicos establecen un marco de cooperación entre las personas y, cuando las leyes son justas, "constituyen las bases sobre las cuales las personas pueden apoyarse unas en otras y objetar con razón cuando sus expectativas no se cumplen"23. Así, este aspecto otorga al Estado de Derecho la capacidad de generar confianza social y, en el caso de las víctimas, "las reparaciones constituyen una manifestación de la seriedad del Estado y de sus conciudadanos en sus esfuerzos por restablecer relaciones de igualdad y respeto" ${ }^{24}$.

Por último, el derecho a la reparación de las víctimas hace referencia a la obligación de los Estados de adoptar medidas "para corregir los distintos daños causados"25. Las reparaciones cumplen, junto a la verdad y a la justicia, un papel fundamental en tanto que suponen un reconocimiento del daño sufrido y una contribución "a la reconstitución o constitución de una nueva comunidad política” 26 ya que son "una forma de reconocer la importancia y valor de las personas"27. Como señala De Greiff, "hay un tipo de injusticia que

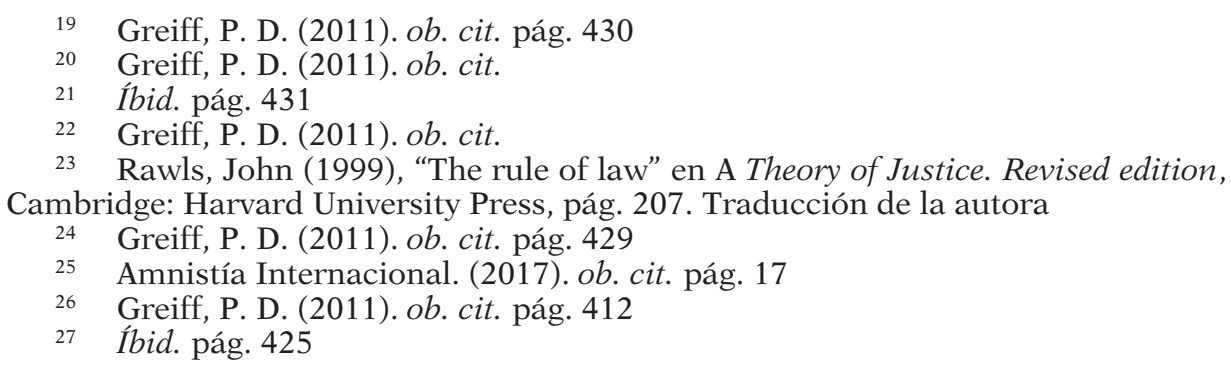


consiste, no en impedir ilegítimamente a una persona el ejercicio de su agencia (...) sino en privarla del tipo de consideración que se debe a quien se ve negativa y gravemente afectado por las acciones del otro" 28 .

\section{En palabras de Jesús Prieto:}

"Cuando las mismas [las víctimas] piden verdad, justicia, memoria, reconocimiento y reparación, están pidiendo un acercamiento, de radical importancia, a esos derechos humanos que sienten haber perdido desde el momento en que fueron, contra su voluntad, convertidos en víctimas. Esta perspectiva nos exige pensar que esas reivindicaciones, además de ser una necesidad para las víctimas, resultan ser una especie de devolución de unos derechos que a ellas no les fueron garantizados"29

De esta forma, los procesos transicionales y los programas de reparación de víctimas inciden ya sea mediante el reconocimiento de la verdad, la justicia o las medidas reparatorias en las tres vertientes de la violencia (directa, estructural y cultural) ${ }^{30}$ en tanto que influyen en el propio sistema y el relato compartido sobre el suceso, garantizando así una paz más amplia y duradera, que va más allá de la concepción limitada de paz como ausencia de violencia directa.

28 Íbid. pág. 424

29 Prieto, J. (2017). El movimiento asociativo y fundacional de las víctimas del terrorismo en Euskadi. [Material de aula] Curso Online Cultura de Paz, Convivencia y Derechos Humanos. Foro de Asociaciones de Educación en Derechos Humanos y por la Paz. pág. 7

30 Por violencia se entienden las "afrentas evitables a las necesidades humanas básicas (...) que rebajan el nivel real de la satisfacción de las necesidades por debajo de lo que es potencialmente posible" (Galtung, J. (2003a). Violencia Cultural. Gernika-Lumo: Gernika Gogoratuz, pág. 8). Johan Galtung diferencia tres tipos de violencias que afectan a la vida de las personas: la directa, la estructural y la cultural. La violencia directa es aquella que se visibiliza a través del comportamiento. Es la más evidente ya que es manifiesta, tanto en acción como en efectos, e intencionada (Galtung, J. (2004). Violencia, guerra y su impacto. Sobre los efectos visibles e invisibles de la violencia). Además de las personas, las estructuras sociales y su funcionamiento pueden generar situaciones en las que se vulneren las necesidades básicas de parte la población. En este caso, la violencia se define como estructural, es decir, está "inserta en los espacios personales, sociales y mundiales" Galtung, J. (2003b). Paz por medios pacíficos: paz y conflicto, desarrollo y civilización. Bilbao: Bakeaz, pág. 57). El tercer y último tipo de violencia perpetúa las dos anteriores, justificándolas, disimulándolas o presentándolas como algo necesario e incluso deseable en según qué contextos. La violencia cultural "sirve para legitimar la violencia directa y estructural, motivando a los actores a cometer violencia directa o a evitar contrarrestar la violencia estructural", de manera consciente o inconsciente (Galtung, J. (2003b) ob. cit.; pág. 57). Estas tres modalidades de violencia se influyen mutuamente y componen lo que el autor denomina "el triángulo de la violencia" (Galtung, J. (2004) ob. cit.). 
ESPAÑA Y SUS VÍCTIMAS. LA PROTECCIÓN DE LAS VÍCTIMAS DEL FRANQUISMO Y...

Por el contrario, "si en un proceso de transición las cuestiones relativas al castigo de los crímenes del pasado no son abordadas con rapidez, pueden volver en formas más perversas pasados los años" ${ }^{31}$.

\section{ESPAÑA Y LA PROTECCIÓN DE LAS VÍCTIMAS: MARCO GENERAL}

La legislación española en materia de protección de las víctimas comenzó a tomar importancia en la década de los años 90 del siglo xx y se caracterizó por una fuerte sectorialización ${ }^{32}$. Así, el estado español fue desarrollando normativas de acompañamiento de víctimas según el ámbito específico, sin contar con un marco común que unificase los derechos de las mismas y los criterios a seguir a la hora de su protección. Esta situación ha derivado en un "efecto asimétrico en estándares de protección" ${ }^{33}$, generando diferencias y discriminaciones entre víctimas según la fuente de la violencia victimizadora ${ }^{34}$.

Esa falta de un marco común quedó suplida en 2015 con la aprobación de la Ley 4/2015, de 27 de abril, del Estatuto de la víctima del delito. De esta forma, "se acaba, en cierto modo, con la anomalía de una sobrerrepresentación de políticas sectoriales de víctimas sin disponer de una regulación que proveyera de los estándares mínimos en consonancia con las corrientes de nuestro entorno jurídico"35. La norma recoge medidas organizativas y derechos procesales y extraprocesales de las personas que han sufrido una vulneración e incluye la posibilidad de su participación en la ejecución de la pena ya que reconoce el derecho de la víctima a recurrir el tercer grado y la libertad condicional en una amplia serie de delitos ${ }^{36}$.

Este nuevo marco unificador, necesario y que pone fin a una anomalía del sistema jurídico español, no termina sin embargo con las desigualdades sectoriales, de manera que se "integra y da carta de naturaleza a distintas velocidades o regímenes de protección" 37 . Esta desigualdad es especialmente patente en los casos de las víctimas de la violencia política en España, cuyos mayores exponentes

31 Chinchón, J. (2012). El tratamiento judicial de los crímenes de la Guerra Civil y el franquismo en España. Una visión de conjunto desde el Derecho Internacional. Bilbao: Universidad de Deusto. pág. 31

32 Landa, J.M. (2018) ob. cit.

33 Íbid. pág. 21

34 Íbid.

35 Íbid. pág. 21

36 Íbid.

37 Íbid. págs. 24-25 
son, por un lado, las víctimas de la Guerra Civil y el franquismo y las víctimas de la organización terrorista ETA.

\section{LAS VÍCTIMAS DE LA GUERRA CIVIL Y EL FRANQUISMO}

Para entender las políticas de memoria histórica desplegadas en España es preciso reparar en el tránsito entre el sistema dictatorial franquista y el democrático, ya que las carencias y limitaciones actuales tienen su origen en ese proceso, en sus acciones y en sus omisiones.

La Transición española ha sido encumbrada como un proceso de transición política ejemplar, fundamentalmente por dos razones: por el consenso alcanzado por unos grupos políticos heterogéneos y la ausencia de violencia con la que se llevó a cabo ${ }^{38}$. Sin embargo, una revisión crítica de los acontecimientos pone en duda dichas afirmaciones ya que, "lejos de ser ejemplar, la Transición española consagró un modelo de impunidad para los criminales de la dictadura" 39 .

El paso de la dictadura a la democracia que se dio en España en 1978 puede definirse como una "transición vía transacción" 40 ya que en estos casos el propio régimen autoritario el que da comienzo al paso de un régimen político a otro, controlando así tanto sus cambios como los tiempos. Este proceso permite a las élites de los estados autoritarios marcar límites y asegurarse cuotas de poder $^{41}$. Este proceso genera una "desigualdad de partida"42 que favorece a las autoridades del régimen dictatorial y que se traduce en una "ausencia de medidas de castigo dirigidas contra los líderes del periodo autoritario"43. A fin de cuentas, "[l]os líderes autoritarios no iniciarán la democratización a no ser que les sea garantizado el que no vayan a ser procesados" 44 .

En el caso español, el control ejercido por las élites franquistas se tradujo en una reinterpretación de la Guerra Civil y el franquismo, así como en la continuidad de símbolos de la dictadura sin

38 Payero, L. (2016) ob. cit.; García de las Heras, M. (2019). "La impunidad de la dictadura franquista: notas sobre la represión y la memoria histórica en la España democrática”. Reflexión Política 21 (43), págs. 37-49.

39 Payero, L. (2016) ob. cit. pág. 212

40 Share, Donald y Mainwaring, Scott (1986) Transiciones vía transacción: la democratización en Brasil y en España, Revista de Estudios Políticos, n 49, pp. 87-135.

41 Íbid.

42 Payero, L. (2016) op. cit. pág. 210

43 Share y Mainwaring (1986), op. cit., pág. 95

44 Íbid. 
una adecuada resignificación desde una perspectiva de memoria histórica ${ }^{45}$. Así, "las reticencias sobre el pasado privilegian una serie de cuestiones políticas en detrimento de la justicia transicional y esta circunstancia evidencia la reproducción de unos imaginarios que enlazan directamente con el franquismo"46, como es la equiparación de las violencias perpetradas por los bandos franquista y republicano durante la guerra mediante una idea de "represión simétrica" 47 y la acción conciliadora de los vencedores tras la guerra, lo que lleva a una "pervivencia simbólica del régimen"48.

En otras palabras:

“(...) para que no hubiera culpables de la guerra era necesario que todos fueran culpables. Se sentaban las bases para entender la Guerra Civil como el resultado de un enfrentamiento fratricida ${ }^{49}$ entre los españoles, un pueblo que aún no había aprendido a convivir pacíficamente. El relato era amable para los hijos de los vencedores, que ganaban en moralidad respecto de sus padres, pero seguía siendo inmoral para la consciencia de los vencidos, culpables solamente de haber intentado defender la legalidad vigente en 1936. Lo relevante en la nueva lectura ya no era el franquismo (...) sino la guerra civil, deseablemente olvidable por cada uno de los bandos y de los individuos que la vivieron"50.

Con todo, respecto al enjuiciamiento de los crímenes franquistas, la transición española estableció un modelo de "olvido del pasado absoluto" en el que se realizó una "renuncia tanto a toda medida de índole sancionadora/reparatoria como a toda forma de investigación y averiguación de la verdad. Todo ello, sin discusión jurídica identificable, públicamente al menos, sobre la viabilidad o licitud internacional de semejante decisión"51.

Una impunidad institucionalizada en la Ley 46/1977, de 15 de octubre, de Amnistía ${ }^{52}$ y que, en línea con el resto de medidas transicionales, generó asimetrías entre las personas a las que se aplicó. "Mientras que los que lucharon contra la dictadura sólo se beneficiaron de la amnistía con respecto a los delitos de intencionalidad política, en el caso de las autoridades, funcionarios y agentes de orden público se amnistiaron "los delitos y faltas que pudieran haber

45 García de las Heras, M. (2019). ob. cit.

46 Íbid. pág. 38

$47 \quad I d$.

48 Íbid. pág. 44

49 Énfasis de la cita original

50 Monedero, Juan Carlos (2014) La transición contada a nuestros padres. Nocturno de la democracia española. Madrid: Los libros de la catarata, pág. 169

51 Chinchón, J. (2012) ob. cit. pág. 32

52 En adelante, la Ley de Amnistía. 
cometido (...) con motivo u ocasión de la investigación y persecución de los actos incluidos en esta Ley" o "contra el ejercicio de los derechos de las personas" 53 .

\section{IV.1. La ley de memoria histórica}

Precisamente, 30 años más tarde de la aprobación de la Ley de Amnistía las Cortes aprobaron la Ley 52/2007, de 26 de diciembre, por la que se reconocen y amplían derechos y se establecen medidas en favor de quienes padecieron persecución o violencia durante la guerra civil y la dictadura ${ }^{54}$, por la que se reconocen y amplían derechos y se establecen medidas en favor de quienes padecieron persecución o violencia durante la guerra civil y la dictadura ${ }^{55}$. Una regulación en la que "el legislador rechazó incorporar la filosofía que está detrás de la recuperación de la memoria histórica para el caso español" 56 y que, en consecuencia, es insuficiente para garantizar los derechos a la verdad, justicia y reparación de las víctimas del franquismo y la Guerra Civil ${ }^{57}$.

Entre los principales déficits de esta legislación ${ }^{58}$ destacan la declaración de ilegitimidad de las sentencias dictadas durante su dictadura, que no su nulidad; el papel de mero colaborador o facilitador que otorga al Estado y las Administraciones Públicas en lo tocante a la exhumación de fosas e identificación de víctimas y una instancia a la retirada de símbolos franquistas de los espacios públicos o su re-

53 De la Cuesta, J. L., \& Odriozola, M. (2018). Marco normativo de la memoria histórica en España: legislación estatal y autonómica. Revista electrónica de Ciencia Penal y Criminología, pág. 5 esta ley).

Más conocida como Ley de Memoria Histórica (en adelante, se referirá así a

55 La aprobación de esta ley sacó de nuevo a relucir las reticencias de parte del espectro político español en lo concerniente a la condena de los crímenes franquistas. "El Partido Popular manifestó inmediatamente su oposición [al Proyecto de ley de la Memoria Histórica], por entender que se trataba de un intento de reconstruir la "Memoria Histórica" y exigir responsabilidad por crímenes pasados, indicando que el Proyecto estaba animado por la venganza, era contrario al espíritu de la transición española, y corría el riesgo de reabrir heridas. Conviene recordar que Fraga Iribarne, ministro de Franco en la década de los sesenta, seguía siendo en esos momentos Presidente Honorario del Partido Popular" en De la Cuesta, J. L., \& Odriozola, M. (2018). ob. cit. pág. 7.

56 Escudero, R. (2018). Memoria histórica e imperio de la ley: el poder judicial ante el derecho a la reparación de las víctimas del franquismo. Derechos y Libertades, $n^{\circ} 38$, pág. 81

57 Íbid.; Payero, L. (2016) ob. cit.; De la Cuesta, J. L., \& Odriozola, M. (2018). ob. cit.

58 Veáse De la Cuesta, J. L., \& Odriozola, M. (2018). ob. cit. 
contextualización, siempre que no se encuentren protegidos por razones artísticas, arquitectónicas o artístico-religiosas ${ }^{59}$. En suma, se trata de una norma que realiza gestos de cara a las demandas de las víctimas, pero desde la equidistancia ${ }^{60}$ y dejando la iniciativa de hacer efectivas las medidas recogidas en el texto en manos de las víctimas, generando así una sensación de "derrota colectiva" ${ }^{1}$.

Javier Chinchón señala a su vez que "es paradigmático que en su literal nunca se hable de obligaciones o derechos, sino sólo de "peticiones o demandas legítimas» de algunos ciudadanos; en un escenario en el que, en lo que especialmente nos ocupa, todo se presenta como si de relaciones entre particulares o sujetos privados se tratase, y en el que el Estado sólo figura como coadyuvante, o en su caso, como sujeto que podrá "establecer subvenciones»"62.

De esta forma, la ley no garantiza el derecho a la verdad de las víctimas en tanto que no incluye ninguna medida de creación de una comisión de la verdad o algún elemento similar, no protege el derecho a la justicia al mantener la vigencia de la Ley de Amnistía y, aunque incluye algunas medidas de reparación económica y moral, son insuficientes dado que no cuenta con un reconocimiento explícito del daño o medidas de homenaje a las víctimas ${ }^{63}$.

\section{IV.2. Judicialización de los crímenes del franquismo}

Con anterioridad a la aprobación de la Ley de Memoria Histórica, las asociaciones de víctimas habían emprendido acciones legales con el objetivo de juzgar en España los crímenes del franquismo. A raíz de las denuncias presentadas en 2006 en la Audiencia Nacional, terminó por establecerse la jurisdicción imperante en el estado en materia de investigación y sanción judicial de las violaciones de derechos humanos perpetradas entre 1936 y 1975, con una consecuencia que niega el derecho a la justicia de las víctimas a través de las instancias judiciales ${ }^{64}$.

59 Íbid.

60 Íbid.

61 Íbid. pág. 32

62 Chinchón, J. (2012) ob. cit. págs. 34-35

63 Escudero, R. (2018) ob. cit.

${ }^{64}$ Íbid.; Ruiz, J. (2017). España: Verdad, Justicia, Reparación y Garantías de no Repetición. Por la Paz, $n^{\circ}$ 31, págs. 18-21. 
Sin entrar en detalle de la evolución de la cuestión y de los argumentos esgrimidos por cada parte ${ }^{65}$, el asunto quedó zanjado con la sentencia del Tribunal Supremo del 27 de febrero de $2012^{66}$, con la que el tribunal español cerró cualquier opción a que los crímenes franquistas fuesen investigados y castigados en España ${ }^{67}$. Para ello, el Tribunal Supremo basaba su decisión en el principio de legalidad que impedía aplicar a los crímenes cometidos entre 1936 y 1975 la categoría de crímenes contra la humanidad (con la consecuente imprescriptibilidad de los delitos) al no estar en aquella época recogida en el Código Penal español la prescripción de los hechos denunciados y la vigencia de la Ley de Amnistía mencionada anteriormente ${ }^{68}$. Además de esta sentencia, el Tribunal Supremo emitió un auto el 28 de marzo de $2012^{69}$ con el que "el TS parece volver a remitir a las víctimas a la «Ley de Memoria Histórica»; esto es, la medida que [...] terminó de convencer a un gran número de ellas de que más allá de lo que el ejecutivo o el legislativo tuvieran a bien querer conceder, la única vía que les quedaba para reclamar plenamente sus derechos eran los tribunales de justicia"70.

Ante esta situación, señala Escudero que "el "impasse" marcado por el Tribunal Supremo para la satisfacción por vía judicial de los derechos a la verdad y a la justicia no afecta al derecho a la reparación, el cual puede y debe ser garantizado por los tribunales ante la inacción de las autoridades y poderes públicos"71.

En resumen, puede afirmarse que "[n]o ha existido en España una política de Estado para responder al derecho de las víctimas a una reparación en sus dimensiones individual y colectiva, y conforme a los

65 Para un análisis más profundo del argumentario presente en los autos y sentencias relativos al tema y la evolución de las causas contra la violencia franquista ver Chinchón, J. (2012). ob. cit.

66 STS (Sala de lo Penal) 813/2012, de 27 de febrero - ECLI:ES:TS:2012:813

67 Chinchón, J. (2012). ob. cit.

68 Chinchón, J. (2012). ob. cit.; Payero, L. (2016) ob. cit.; De la Cuesta, J. L., \& Odriozola, M. (2018). ob. cit.

Para ver algunas propuestas de superación de estas limitaciones ver Payero, L. (2016) ob. cit., especialmente las páginas 222-230. Es interesante la propuesta de Gil recogida en el texto con relación a la aplicación de la Ley de Amnistía. "La amnistía no impide la investigación y constatación de los hechos y del móvil político para los delitos de los funcionarios que no hubieran sido perseguidos con anterioridad, sino que, por el contrario, la constatación por el tribunal de estos presupuestos es condición para su aplicación. Esa interpretación acercaría más nuestra Ley de Amnistía a un mecanismo de averiguación de la verdad y no de olvido absoluto" (Gil, 2009, pág. 86 en Payero, L. (2016) ob. cit., pág. 217).

69 Auto del TS de 28 de marzo de 2012, número de recurso: 20380/2009

70 Chinchón, J. (2012). ob. cit. pág. 128

71 Escudero, R. (2018) ob. cit. pág. 75 
componentes exigidos por las normas internacionales. La respuesta del Estado español hacia las víctimas de la Guerra Civil y del franquismo ha sido bajo categorías que no dan cuenta de la naturaleza y la gravedad de los hechos ilícitos reconocidos como tales por el derecho internacional. Los limitados reconocimientos simbólicos o económicos han sido desarticulados, insuficientes y tardíos"72 y la Ley de Memoria Histórica no consigue paliar todas esas graves carencias ${ }^{73}$. "La misma esencia y configuración del deber de reparar de ninguna forma puede acabar convirtiéndose en un mero acto discrecional del Estado; el concepto de víctima no puede pervertirse presentándola simplemente como receptora de la ayuda o la generosidad estatal; la violación de una obligación internacional no puede, en definitiva, considerarse como un infortunio, una fatalidad o un revés del destino" ${ }^{74}$.

\section{LAS VÍCTIMAS DE ETA}

La vida política del País Vasco ha estado marcada durante los últimos casi 60 años por el conflicto armado entre el grupo armado ETA y el gobierno español. Una violencia directa que evidencia la existencia de un conflicto político de más calado, el de la demanda de la independencia y el derecho a la autodeterminación de la población nacionalista vasca, y que ha causado más de 800 víctimas mortales $^{75}$.

72 Amnistía Internacional (2005) España: poner fin al silencio y a la injusticia. La deuda pendiente con las víctimas de la guerra civil española y del régimen franquista págs. 63-64

73 Naciones Unidas ha mostrado en diversas ocasiones su preocupación por la falta de justicia transicional en España en relación a los crímenes del franquismo e insta al gobierno a tomar medidas para paliar esta situación en las recomendaciones de sus informes de seguimiento, como el EPU o los informes del Relator Especial sobre la promoción de la verdad, la justicia, la reparación y las garantías de no repetición (A/HRC/27/56/Add.1 (2014) Informe del Relator Especial sobre la promoción de la verdad, la justicia, la reparación y las garantías de no repetición, Asamblea General de las Naciones Unidas; A/HRC/WG.6/35/L (2020) Draft report of the Working Group on the Universal Periodic Review Spain,Working Group on the Universal Periodic Review, Human Rights Council).

74 Chinchón, J. (2012). ob. cit. pág. 38. Las legislaciones desarrolladas en esta materia a nivel autonómico han logrado suplir algunas de las carencias de la Ley de Memoria Histórica, llegando algunas de ellas a superar en protección y garantías la propia normal estatal (De la Cuesta, J. L., \& Odriozola, M. (2018). ob. cit.).

75 El recuento de víctimas varía según la fuente consultada y el Gobierno español no ofrece datos oficiales (Amnistía Internacional. (2017). ob. cit.). 
En paralelo al diseño de una legislación de excepción ${ }^{76}$ para luchar contra la violencia de ETA, el Gobierno español ha desarrollado importantes políticas de protección y reconocimiento de las víctimas del terrorismo. "Se trata del ámbito sectorial de protección que más ha entronizado y situado a las víctimas en el imaginario colectivo hasta el punto de que probablemente ha sido y sigue siendo la "víctima" por excelencia"77.

Sin embargo, esta legislación no responde a una lógica de justicia transicional o de reparación de todas las víctimas del conflicto ya que realiza importantes diferenciaciones entre las víctimas de la violencia de ETA y las víctimas de otras violencias ${ }^{78}$. Mientras se encumbra a las personas que han sufrido algún tipo de victimización por la violencia de la organización vasca, desprotege a las víctimas de agentes que contaron con el visto bueno estatal o de miembros de las fuerzas de seguridad del Estado ${ }^{79}$.

El marco normativo a nivel estatal con relación a las víctimas del terrorismo está compuesto por la Ley 29/2011 del 22 de septiembre de Reconocimiento a las Víctimas del Terrorismo ${ }^{80}$ y el Real Decreto 671/2013, de 6 de septiembre, por el que se aprueba el Reglamento

76 Una legislación de excepción de dudoso compromiso con los derechos humanos (Aministía Internacional (2017) ob. cit.) acerca de la que Naciones Unidas ha mostrado su preocupación en diversas ocasiones, especialmente, en relación a la tipificación de los delitos de terrorismo y tortura en el Código Penal español, las investigaciones de denuncias de malos tratos de personas detenidas o el régimen de incomunicación que se aplica a las personas acusadas por crímenes relacionados con el terrorismo (A/HRC/10/3/Add.2 (2008) Informe del Relator Especial sobre la promoción y la protección de los derechos humanos y las libertades fundamentales en la lucha contra el terrorismo, Consejo de Derechos Humanos); A/HRC/27/56/Add.1 (2014) ob. cit.; A/HRC/WG.6/35/L (2020) ob. cit.). Precisamente, España ha sido condenada en diversas ocasiones por el Tribunal Europeo de Derechos Humanos (TEDH) por no investigar denuncias de torturas (Amnistía Internacional. (2017).ob. cit.).

77 Landa, J.-M. (2017). Leyes de víctimas y derecho penal: simetrías y asimetrías con especial atención a la violencia política. [Material de aula] Curso Online Cultura de Paz, Convivencia y Derechos Humanos. Foro de Asociaciones de Educación en Derechos Humanos y por la Paz.

78 En este sentido, las políticas desarrolladas por el Gobierno Vasco con relación al conflicto sí están basadas en los estándares establecidos desde Naciones Unidas, enfocadas a la reparación, la verdad y la justicia (Landa, J.-M. (2018), ob. cit.; Hernando, M. (2017). Experiencias con las víctimas en el ámbito institucional: bases principales líneas de actuación. [Material de aula] Curso Online Cultura de Paz, Convivencia y Derechos Humanos. Foro de Asociaciones de Educación en Derechos Humanos y por la Paz).

79 Amnistía Internacional. (2017). ob. cit.; Landa, J.-M. (2018) ob. cit.

80 Esta ley sustituyó y amplió la Ley 32/1999, de 8 de octubre, de Solidaridad con las víctimas del terrorismo (Landa, J.-M. (2017) ob. cit.). En adelante, se referirá a la Ley 29/2011 como Ley de las Víctimas del Terrorismo. 
de la Ley 29/2011, de 22 de septiembre, de Reconocimiento y Protección Integral a las Víctimas del Terrorismo ${ }^{81}$. Este cuerpo normativo garantiza a las víctimas prestaciones individuales, protección ante símbolos ofensivos, protección procesal, homenajes y una tutela penal y administrativa específica ${ }^{82}$.

La combinación normativa en materia antiterrorista y de protección de las víctimas genera un marco en el que los derechos a la verdad, justicia y reparación de las víctimas de la violencia de ETA quedan reconocidos y amparados, ya que los crímenes de ETA son juzgados y sus responsables condenados, las personas sufridoras de la violencia reciben prestaciones y cuentan con gran reconocimiento social, al tiempo que están protegidas contra discursos de odio que enaltezcan el terrorismo o las humillen por su condición de víctima, por citar algunos aspectos.

Ese conjunto regulador deja fuera de la consideración de víctima y, por consiguiente, niega los derechos a la verdad, justicia y reparación, a las personas que han sufrido tortura a manos de fuerzas de seguridad del Estado y a las que fueron objetivo de la violencia de otros grupos armados que actuaron en el marco del conflicto, como son los Grupos Antiterroristas de Liberación (GAL) ${ }^{83}$ y otros grupos de extrema derecha ${ }^{84}$. A algunas de esas víctimas se les ha llegado a denegar ayudas porque la Subdirección General de Apoyo a Víctimas del Terrorismo "consideró que las personas fallecidas lo hicieron como consecuencia de actos terroristas, por lo que sus familiares no reunían los requisitos para ser beneficiarios de la indemnización solicitada", dando por hecho que las personas fallecidas pertenecían a alguna organización terrorista ${ }^{85}$.

Por lo tanto, las víctimas amparadas bajo la consideración de víctimas del terrorismo, es decir, las víctimas de la violencia de ETA, cuentan con la protección de sus derechos a la verdad, justicia y reparación, a pesar de quedar aún camino por recorrer ${ }^{86}$. Sin

81 Hernando, M. (2017). ob. cit.

82 Landa, J.-M. (2018) ob. cit.

83 Los GAL fueron una organización contraterrorista formada por "miembros de los cuerpos de seguridad del Estado y pistoleros a sueldo que bajo el conocimiento de altos cargos del gobierno llevaron a cabo atentados indiscriminados" (Amnistía Internacional. (2017). ob. cit. pág. 12).

84 Batallón Vasco Español, Triple A, Grupos armados españoles, Acción nacional española, Grupo Antiterrorismo ETA y Guerrilleros de Cristo Rey (Íbid.).

85 Íbid. pág. 39

86 Aun existen casos de violaciones de derechos cometidas por la organización vasca que no han sido resueltos por la justicia (véase Carmena, M., Landa, J. M., Múgica, R., \& Uriarte, J. M. (2013). Euskal kasuan gertaturiko giza eskubideen 
embargo, otra parte importante de las víctimas del conflicto queda desprotegida, por lo que la protección de las víctimas del terrorismo o del conflicto vasco es limitada y parcial.

Esta situación supone una omisión de sus deberes por parte estado español y un acto discriminatorio, ya que "en el marco de las obligaciones de España (...) deben incluirse también a las víctimas de las vulneraciones de derechos humanos cometidas por otros grupos armados, así como el alcance y la responsabilidad del Estado en estos casos"87.

La interpretación restrictiva que realiza el Estado español sobre la consideración de víctimas en el caso de ETA está estrechamente ligada a la concepción del propio conflicto $^{88}$. Ante la violencia de la organización armada, el gobierno español ha optado por centrar el conflicto en la propia existencia del grupo armado, sin reconocer la naturaleza política que llevó al surgimiento del mismo. La falta de acuerdo en si ETA es la manifestación violenta de un conflicto político sin resolver o terrorismo criminal ha tenido a lo largo de los años un impacto directo en las dificultades para desarrollar una estrategia contra el grupo armado y para plantear una solución ${ }^{89}$.

"La aproximación a la violencia de ETA en términos exclusivos de terrorismo ha significado el desarrollo de un marco dominante de antiterrorismo. También ha permitido a España identificar todo el nacionalismo vasco contaminado de terrorismo a diferentes niveles y no como la profunda cuestión social que es hoy en día"90. Bajo el paraguas de esta perspectiva, el gobierno español ha desarrollado una legislación de excepción cuya amplia interpretación

urraketei buruzko oinarrizko txostena (1960-2013). Vitoria-Gasteiz: Bakegintza eta Bizikidetzarako Idazkaritza Nagusia, Eusko Jaurlaritza) y aún quedan pasos que dar para una total reconciliación, especialmente en el País Vasco.

87 Amnistía Internacional (2017) ob. cit. pág. 37

88 El análisis de las posiciones y percepciones de los diferentes actores en un conflicto es indispensable para contar con una reconstrucción lo más completa posible de los hechos. Como indica Lederach, un conflicto es un proceso, es decir, "evoluciona por la constante interacción humana actual y él mismo modifica continuamente a las personas que le dieron vida, ejerciendo un efecto en el entorno social en el que nace, se desarrolla y quizás muere" (Lederach, J.P. (1998) Construyendo la paz: reconciliación sostenible en sociedades divididas Bilbao:Bakeaz, pág. 92), por lo que "la forma de cada uno de los implicados de percibir el conflicto, los objetivos, las intenciones y motivos del otro determinará la intensidad de la contienda" (Lederach, J.P. (2000) El abecé de la paz y los conflictos, Madrid: Catarata, págs.. 57-58) y el relato en torno al conflicto.

${ }_{89}$ Withfield, T. (2015). The Basque Conflict and ETA: The Difficulties of an Ending. Special Report $n^{\circ} 384$. United States Institute for Peace.

90 Íbid. pág. 5. Traducción de la autora. 
ha derivado, en muchas ocasiones, en castigos por asociación más que por responsabilidades penales ${ }^{91}$ como las ilegalizaciones de formaciones políticas, juveniles o el cierre de periódicos.

Con esta interpretación del conflicto, la protección de las víctimas se centra en aquellas que han sido objetivo de las acciones violentas de la organización vasca, pero no aquellas que también han sufrido vulneraciones a manos de otros victimarios en el mismo contexto de conflicto político armado y, en consecuencia, complica la solución del propio conflicto más allá de la violencia ${ }^{92}$.

\section{VÍCTIMAS DE PRIMERA Y DE SEGUNDA}

Los dos casos anteriormente expuestos presentan evidentes diferencias, pero a la vez comparten un rasgo significativo: la ausencia de procesos de justicia transicional que lleven a la reconciliación de la sociedad.

Naciones Unidas define la justicia transicional como "la variedad de procesos y mecanismos asociados con los intentos de una sociedad por resolver los problemas derivados de un pasado de abusos a gran escala, a fin de que los responsables rindan cuentas de sus actos, servir a la justicia y lograr la reconciliación. Tales mecanismos pueden ser judiciales o extrajudiciales" ${ }^{\prime 3}$.

Sin embargo, aunque España ha vivido dos situaciones de graves violaciones de los derechos humanos, no se han desarrollado programas de reconstrucción de paz a nivel estatal que se hayan saldado con una reconciliación, entendida como el "proceso de abordar relaciones conflictivas y fracturadas después del conflicto político" ${ }^{94}$.

91 Íbid.

92 Withflied, T. (2015). ob. cit. Esta perspectiva afecta también a las medidas llevadas a cabo desde el gobierno central para avanzar en la reconstrucción de paz. El proceso de paz en el País Vasco fue un proceso de paz "virtual" (Íbid.), ya que no se ha llevado a cabo un proceso de negociaciones similar a otros conflictos armados internos, como puede ser el caso de Irlanda del Norte que finalizó con el Acuerdo de Viernes Santo de 1998 o el de Colombia, con los Acuerdos de Paz entre gobierno y las Fuerzas Armadas Revolucionarias de Colombia (FARC), que suelen incluir medidas de justicia transicional y restaurativa como parte del escenario postviolencia.

93 Naciones Unidas (2004) El Estado de derecho y la justicia de transición en las sociedades que sufren o han sufrido conflictos, Informe del Secretario General (UN Doc $\mathrm{S} / 2004 / 616) \S 8$

${ }_{94}$ Hamber, B., \& Kelly, G. (2018). La paradoja de la reconciliación. Por la paz, no34, pág. 5 
Ante la falta de procesos transicionales, en el estado español predomina un modelo desigual ${ }^{95}$, ya sea en materia de protección de las víctimas como en la persecución de los delitos ${ }^{96}$. "El modelo jurídico excepcional de enfrentamiento de los potenciales enemigos de la democracia y de acompañamiento a sus víctimas prototípicas no está como en Europa inspirado en el holocausto nazi —o sus categorías equivalentes de crímenes contra la humanidad y de guerra- sino en el terrorismo de ETA"97. De esta forma, "el Código Penal [...] materializa y ahorma asimetrías de protección de mayor y menor intensidad que tienden a destilar preferencias ideológicas o, al menos, preferencias de política criminal según la índole delictiva que deparan estándares de protección muy diferenciados"98.

Las reticencias y lentitud de las medidas a favor de las víctimas del franquismo contrastan con el reconocimiento y protección ofrecidas a las víctimas de ETA, que no del conflicto vasco en su conjunto. En ambos casos, sin embargo, es necesario subrayar el papel que las asociaciones de víctimas han tenido en el avance en materia de legislación sobre víctimas ${ }^{99}$, aunque con presencia y capacidad de influencia desiguales ${ }^{100}$.

\section{CONCLUSIONES}

Con lo expuesto anteriormente es notorio que, respecto a España, no puede decirse de manera generalizada que las víctimas de

95 Payero, L. (2016) ob. cit.

96 Muestra de las diferentes sanciones de los actos relacionados con uno y otro caso son la existencia de un delito de enaltecimiento y apología del terrorismo cuya amplia interpretación entra en conflicto con la libertad de expresión, especialmente en un contexto sin violencia, que contrasta con la ausencia de tipificación de un delito similar con relación al franquismo y el debate en torno a la idoneidad de convertirlo en delito. Algunas muestras de las diferentes posturas pueden consultarse en estos links: https://www.publico.es/politica/prohibir-apologiafranquismo-medida-necesaria-populismo-punitivo.html; https://elpais.com/politica/2020/02/10/actualidad/1581362186_653599.html o https://www.elperiodico.com/ es/politica/20200223/apologia-franquismo-codigo-penal-delito-7859252.

97 Landa, J.-M. (2018) ob. cit. pág. 37

98 Íbid. pág. 39

99 Chinchón, J. (2012). ob. cit.; Mínguez, X. (2015) ob. cit.

100 Por ejemplo, Landa identifica la inclusión en el Estatuto de la Víctima la capacidad de las víctimas de recurrir el tercer grado o la libertad condicional de los condenados con las "reivindicaciones de algunas asociaciones de víctimas del terrorismo" (Landa, J.-M. (2018) ob. cit. pág. 24), mientras que los grupos a favor de la Memoria Histórica criticaron no haber sido consultados para la redacción de la Ley de 2007 (De la Cuesta, J. L., \& Odriozola, M. (2018). ob. cit.). 
violaciones graves de derechos humanos tienen garantizados sus derechos y que reciben las reparaciones acordes.

Por el contrario, queda en evidencia que la protección de las víctimas responde a modelos desiguales, que diferencia el alcance de los derechos de las personas que han sufrido la violencia según el origen de la misma, especialmente cuando ésta proviene de los órganos estatales o cuenta con su consentimiento, sea en el contexto de la Guerra Civil y la dictadura o en el marco del conflicto vasco.

El olvido de las víctimas del franquismo y el ensalzamiento de las víctimas de ETA no es casual, sino que sirve al estado español para apuntalar el falso ideal de la transición pacífica entre un régimen dictatorial a uno democrático. Así lo señala también Jesús Izquierdo, quien "interpreta el reconocimiento de las víctimas de ETA al máximo nivel y la postergación de las víctimas de la guerra civil y la represión franquista en clave de una lectura de la transición española en que se impulsa una suerte de narrativa bíblica (Pecado-Expulsión del Paraíso-Redención) secularizada, con el fin de blanquear las responsabilidades por las graves violaciones de derechos humanos cometidas y, también, como resultado del trauma que el "genocidio $^{101 "}$ franquista ha supuesto" 102 .

Así, ante una transición que primó la impunidad frente al derecho a la verdad, justicia y reparación de las víctimas del franquismo, España encontró un enemigo en el que representar lo "antidemocrático" y no prestar atención a los crímenes franquistas. "El terrorismo

101 La Convención para la Prevención y Sanción del Delito de Genocidio de Naciones Unidas define el genocidio en su artículo 2 de la siguiente manera:

(...) se entiende por genocidio cualquiera de los actos mencionados a continuación, perpetrados con intención de destruir total o parcialmente, a un grupo nacional, étnico, racial o religioso como tal: a) Matanza de miembros del grupo; b)Lesión grave de a la integridad física o mental de los miembros del grupo; c) Sometimiento intencional del grupo a condiciones de existencia que hayan de acarrear su destrucción física, total o parcial; d) Medidas destinadas a impedir los nacimientos en el seno del grupo; e)Traslado por la fuerza de niños del grupo a otro grupo. (Convención para la Prevención y Sanción del Delito del Genocidio de Naciones Unidas A/RES/260(III), Asamblea General de las Naciones Unidas, 1948). Esta definición resalta no sólo los actos que comprenden genocidio, sino que subraya la necesidad de que exista una intención expresa de destruir a un grupo concreto para que dichos actos puedan calificarse de genocidio. Una tipificación aplicable a los crímenes franquistas, ya que la violencia de la Guerra Civil y la posterior dictadura estuvo dirigida a acabar, principalmente, con la disidencia política y las personas defensoras de la democracia republicana (Miguez Macho, A. (2012) Una genealogía genocida del franquismo. Revista de Estudios sobre genocidio. Vol. 8 págs. 9-26; López, P. (2012) Los crímenes del franquismo y el derecho internacional. Derecho y Realidad n²0 págs, 279-318).

102 Landa, J.-M. (2018) ob. cit. pág. 26. 
desarrollado por grupos con diferentes ideologías en el contexto del cambio político favorece la generalización de una narrativa moderada dirigida a desdeñar el pasado franquista bajo el pretexto de eludir viejas confrontaciones" ${ }^{103}$.

De esta forma, el Estado y la sociedad civil, receptores de la violencia de ETA, conformaban un "nosotros" caracterizado por los valores democráticos y el respeto de los derechos, mientras que ETA y su entorno representaban el "otro" a eliminar, los asesinos contrarios a la "democracia" (con la importante connotación de esa palabra en el imaginario de una sociedad recién salida de una violenta dictadura). Al mismo tiempo, la continuidad de la actividad armada en democracia trajo ventajas políticas para los gobiernos estatales ya que "la persistencia de ETA ha prevenido la formación de una amplia alianza entre los nacionalistas vascos y ha permitido a los sucesivos gobiernos en Madrid desestimar las demandas nacionalistas. Por lo tanto, la acción contra ETA ha descansado sobre un entendimiento tácito en algunos ámbitos de que la continuación de la violencia de ETA en un nivel bajo y manejable era posiblemente la opción menos mala disponible"104.

En medio de este aprovechamiento político del contexto quedaron las víctimas, cuyos derechos no dependen de su condición de personas sufridoras de una vulneración de derechos fundamentales, sino de a manos de quién se han convertido en víctimas. Una diferenciación arbitraria que, además de ir en contra de la legislación internacional en materia de víctimas, supone una nueva vulneración de los derechos de esas personas, con lo que la lista de agravios aumenta y el alcance y secuelas del daño causado crecen y se perpetúan.

Ante esta situación, son indispensables sendos procesos transicionales basados en los derechos de las víctimas, de todas ellas, pero que no olviden los derechos de los victimarios, para que España pueda saldar cuentas con su pasado más cercano, marcado por violencias de signo diverso, y avanzar así en la consolidación de una democracia verdadera y una paz efectiva, en la que los derechos de unas víctimas no escondan o releguen a un segundo plano los derechos de otras.

A fin de cuentas, para el desarrollo de una cultura política verdaderamente democrática es imprescindible conocer el pasado y, es-

103 García de las Heras, M. (2019) ob. cit. pág. 40

104 Withfield, T. (2015) ob. cit. pág. 11. Traducción de la autora. 
pecialmente en casos de violencias de este tipo, contar con memoria histórica compartida ${ }^{105}$. Este planteamiento exige simultáneamente la evaluación crítica de la historia, porque el pasado representa "una dimensión permanente de la conciencia humana, un componente inevitable de las instituciones, valores y otros patrones de la sociedad humana" 106 .

"La paz no será real, ni completa, si se construye sobre el olvido de quienes directa y personalmente han sufrido la violencia"

Fernando Buesa, $1999^{107}$

\section{BIBLIOGRAFÍA}

Amnistía Internacional. (2005). España: poner fin al silencio y a la injusticia. La deuda pendiente con las víctimas de la guerra civil espanola y del régimen franquista.

Amnistía Internacional. (2007). Verdad, Justicia y Reparación. Creación de una Comisión de la verdad efectiva. London: Aministía Internacional.

Amnistía Internacional. (2017). Afrontar el pasado para construir el futuro: Verdad, justicia y reparación en el contexto del País Vasco. Madrid: Amnistía Internacional.

Carmena, M., Landa, J. M., Múgica, R., \& Uriarte, J. M. (2013). Euskal kasuan gertaturiko giza eskubideen urraketei buruzko oinarrizko txostena (1960-2013). Vitoria-Gasteiz: Bakegintza eta Bizikidetzarako Idazkaritza Nagusia, Eusko Jaurlaritza.

Chinchón, J. (2012). El tratamiento judicial de los crímenes de la Guerra Civil y el franquismo en España. Una visión de conjunto desde el Derecho Internacional. Bilbao: Universidad de Deusto.

Comisión Interamericana de Derechos Humanos. (2014). Derecho a la verdad en América Latina. OEA/Ser.L/V/II.152

CRUZ, L. M. (2010). El derecho de reparación de las víctimas en el derecho internacional. Un estudio comparativo entre el derecho internacional de responsabilidad estatal y los principios básicos de

105 Reig, A. (2017) La maldita memoria histórica en La crítica de la crítica. Inconsecuentes, insustanciales, impotentes, prepotentes y equidistantes Madrid: Siglo XXI págs. 169-183

106 Hobsbawm, E. J. (1972). The Social Function of the Past: some questions. Past \& Present, $\mathrm{n}^{\circ}$ 55, pág. 3

107 Prieto, J. (2017) ob. cit. pág. 15 
reparación de víctimas de derechos humanos. Revista de Derecho Político, 185-209.

De la Cuesta, J. L., \& Odriozola, M. (2018). Marco normativo de la memoria histórica en España: legislación estatal y autonómica. Revista electrónica de Ciencia Penal y Criminología.

Escudero, R. (2018). Memoria histórica e imperio de la ley: el poder judicial ante el derecho a la reparación de las víctimas del franquismo. Derechos y Libertades, $n^{\circ} 38,73-105$.

Galtung, J. (2003a). Violencia Cultural. Gernika-Lumo: Gernika Gogoratuz. Obtenido de https://www.gernikagogoratuz.org/wp-content/uploads/2019/03/doc-14-violencia-cultural.pdf

Galtung, J. (2003b). Paz por medios pacíficos: paz y conflicto, desarrollo y civilización. Bilbao: Bakeaz.

Galtung, J. (2004). Violencia, guerra y su impacto. Sobre los efectos visibles e invisibles de la violencia. Obtenido de https://them.polylog. org/5/fgj-es.htm

García de las Heras, M. (2019). La impunidad de la dictadura franquista: notas sobre la represión y la memoria histórica en la España democrática. Reflexión Política 21 (43), 37-49.

GREIFF, P. D. (2011). Justicia y reparaciones. En E. F. Reátegui, Justicia transicional: manual para América Latina (págs. 407-440). Brasilia: Comisión de Amnistía, Ministerio de Justicia; Nueva York: Centro Internacional para la Justicia Transicional.

Hamber, B., \& Kelly, G. (2018). La paradoja de la reconciliación. Por la paz, $n^{\circ} 34,5-11$.

HernANDo, M. (2017). Experiencias con las víctimas en el ámbito institucional: bases principales líneas de actuación. [Material de aula] Curso Online Cultura de Paz, Convivencia y Derechos Humanos. Foro de Asociaciones de Educación en Derechos Humanos y por la Paz.

Hobsbawn, E. J. (1972). The Social Function of the Past: Some Questions. Past \& Present(55), 3 - 17.

LANDA, J.-M. (2017). Leyes de víctimas y derecho penal: simetrías y asimetrías con especial atención a la violencia política. [Material de aula] Curso Online Cultura de Paz, Convivencia y Derechos Humanos. Foro de Asociaciones de Educación en Derechos Humanos y por la Paz. 
ESPAÑA Y SUS VÍCTIMAS. LA PROTECCIÓN DE LAS VÍCTIMAS DEL FRANQUISMO Y...

LANDA, J.-M. (2018). Políticas de víctimas de la violencia política en España y el País Vasco: una reflexión a la luz del holocausto. Revista General de Derecho Penal, $n^{\circ} 29$.

LEDERACH, J. P. (1998). Construyendo la paz: reconciliación sostenible en sociedades divididas. Bilbao: Bakeaz.

Lederach, J. P. (2000). El abecé de la paz y los conflictos. Madrid: Catarata.

LóPez, P. (2012). Los crímenes del franquismo y el derecho internacional. Derecho y Realidad(20), 279-318.

Míguez, A. (2012). Una genealogía genocida del franquismo. Revista de Estudios sobre Genocidio, 8, 9-26.

Mínguez, X. (2015). Euskal Herria. Algunas claves para avanzar en la construcción de paz. En E. Mundubat, Aprendiendo de los procesos de paz. Bilbao: Mundubat.

Mínguez, X. (2017). Iniciativas sociales, institucionales y educativas a favor de la paz en Euskadi. [Material de aula] Curso Online Cultura de Paz, Convivencia y Derechos Humanos. Foro de Asociaciones de Educación en Derechos Humanos y por la Paz.

Monedero, J. C. (2014). Un 'pacto de amnesia colectiva'. En La transición contada a nuestros padres. Nocturno de la democracia española (págs. 167-182). Madrid: Los libros de la Catarata.

Payero, L. (2016). Justicia de Transición en España: claves para aprobar una asignatura pendiente. Revista de Paz y Conflictos, $n^{\circ} 1$, vol. 9, 209-234.

Prieto, J. (2017). El movimiento asociativo y fundacional de las víctimas del terrorismo en Euskadi. [Material de aula] Curso Online Cultura de Paz, Convivencia y Derechos Humanos. Foro de Asociaciones de Educación en Derechos Humanos y por la Paz.

Rawls, J. (1999). The rule of law. En A Theory of justice. Revised edition (págs. 206-213). Cambridge: Harvard University Press.

ReIG, A. (2017). La maldita memoria histórica. En La crítica de la crítica. Inconsecuentes, insustanciales, impotentes, prepotentes y equidistantes (págs. 169-183). Madrid: Siglo XXI.

RuIz, J. (2017). España: Verdad, Justicia, Reparación y Garantías de no Repetición. Por la Paz, $n^{\circ} 31,18-21$. 
SHARE, D., \& Mainwaring, S. (1986). Transiciones vía transacción: la democratización en Brasil y en España. Revista de Estudios Políti$\cos (49), 87-135$.

Withfield, T. (2015). The Basque Conflict and ETA: The Difficulties of an Ending. Special Report $n^{\circ} 384$. United States Institute for Peace., En línea en: https://www.usip.org/sites/default/files/SR384The-Basque-Conflict-and-ETA-The-Difficulties-of-An-Ending.pdf.

\section{Otros documentos referenciados}

Convención para la Prevención y Sanción del Delito del Genocidio de Naciones Unidas A/RES/260(III) (Asamblea General de las Naciones Unidas, 9 de diciembre de 1948)

Draft report of the Working Group on the Universal Periodic Review, Spain, A/HRC/WG.6/35/L. (Working Group on the Universal Periodic Review, Human Rights Council January de 2020).

El Estado de derecho y la justicia de transición en las sociedades que sufren o han sufrido conflictos, UN Doc S/2004/616 (Naciones Unidas 2004).

Informe del Relator Especial sobre la promoción de la verdad, la justicia, la reparación y laas garantías de no repetición, A/HRC/27/56/Add.1 (Asamblea General de las Naciones Unidas 22 de julio de 2014).

Informe del Relator Especial sobre la promoción y la protección de los derechos humanos y las libertades fundamentales en la lucha contra el terrorismo, A/HRC/10/3/Add.2 (Consejo de Derechos Humanos 16 de diciembre de 2008).

Principios y directrices básicos sobre el derecho de las víctimas de violaciones manifiestas de las normas internacionales de derechos humanos y de violaciones graves del derecho internacional humanitario a interponer recursos y obtener repar, A/RES/60/147 (Asamblea de Naciones Unidas 16 de Diciembre de 2005). Obtenido de https://www.ohchr.org/SP/ProfessionalInterest/Pages/RemedyAndReparation.aspx 